
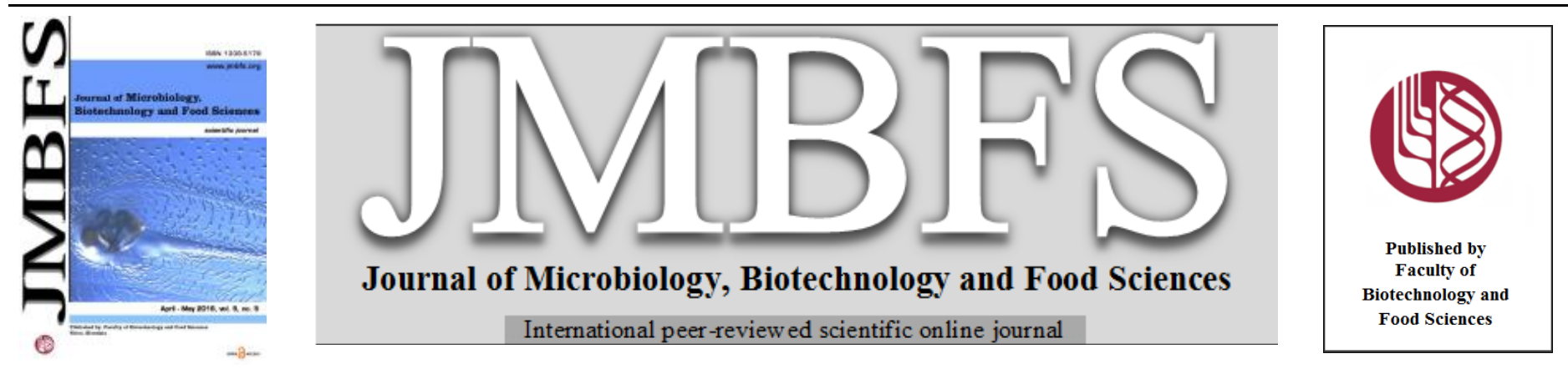

\title{
ANTIBACTERIAL ACTIVITY OF CARAWAY ESSENTIAL OIL AGAINST STAPHYLOCOCCUS AUREUS ISOLATED FROM PATIENTS WITH FURUNCULOSIS
}

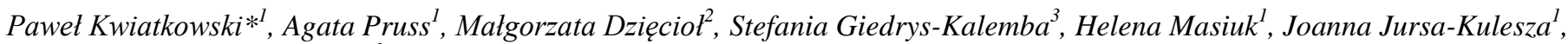 Iwona Wojciechowska-Koszko ${ }^{l}$}

\author{
Address(es): Paweł Kwiatkowski, MSc, \\ ${ }^{1}$ Department of Microbiology and Diagnostic Immunology, Pomeranian Medical University, 72 Powstańców Wlkp. Avenue, $70-111$ Szczecin, Poland. \\ ${ }^{2}$ Institute of Organic Chemical Technology, West Pomeranian University of Technology, Szczecin, 42 Piastów Avenue, $71-065$ Szczecin, Poland. \\ ${ }^{3}$ ALAB Laboratories Ltd., 22/30 Stępińska Street, 00-739 Warsaw, Poland.
}

*Corresponding author: pawel.kwiatkowski@ pum.edu.pl

doi: $10.15414 / j m b f s .2016 .5 .5 .482-486$

\section{ARTICLE INFO}

Received 26. 8. 2015

Revised 13. 12. 2015

Accepted 5. 1. 2016

Published 1. 4. 2016

Regular article

open $O$ access

\begin{abstract}
Furunculosis is a common skin disease caused by Staphylococcus aureus. Infection is characterized by a deep inflammation of the hair follicle. It leads to abscess formation with accumulation of pus and necrotic tissue. Treatment with antibiotics is often ineffective and patients often suffer from recurrent episodes. The aim of the study was to determine the antibacterial activity of caraway essential oil (CEO) against $S$. aureus isolated from patients with furunculosis. S. aureus strains were characterized by a different virulence factors and resistance to antibiotics. Effect of CEO was evaluated against 15 strains of $S$. aureus isolated from patients and against 3 control strains. The susceptibility to antibiotics was determined using Kirby-Bauer disk diffusion method. The presence of genes encoding virulence factors was determined with PCR method. The presence of slime was examined with Congo red method. The composition of the CEO was evaluated by gas chromatography method with mass selective detector. The minimum inhibitory concentration (MIC) of CEO was determined by serial dilutions in tryptic soy broth containing 10\% NaCl. Analysis of the oil composition showed that the predominant component was cuminaldehyde $(46.7 \%)$. CEO showed inhibition activity against control strains and patients strains. The MIC values of essential oil ranged from 10 to $12 \mu \mathrm{L} / \mathrm{mL}$ and from 7 to $67 \mu \mathrm{L} / \mathrm{mL}$, respectively. Lack of correlation between the antibiotic resistance of the bacterial strains, presence of genes, presence of slime and their sensitivity to essential oil was found. CEO can be used as alternative antibacterial agent in supportive treatment patients with furunculosis.
\end{abstract}

Keywords: Staphylococcus aureus, Carum carvi, caraway oil, essential oil, furunculosis

\section{INTRODUCTION}

Furunculosis (boils) is a common skin disease caused by Staphylococcus aureus. This infection is characterized by painful and deep infections of the hair follicle. Even mild lesions are very painful and often leave a scars. Many furunculosis strains acquired resistance to different antibiotics. Therefore, antibiotic treatment is frequently not effective, especially in patients who suffer from recurrent episodes (El-Gilany \& Fathy, 2009; Holtfreter et al., 2011). Recurrence of boils is an occurrence of many lesions over a period of months or years, in the same patient. Boils are often located on the limbs and neck, and leave a scar after recovery (Demos et $\boldsymbol{a l}$., 2012). If several adjacent lesions are coalesced form carbuncles as a result (Ibler \& Kromann, 2014).

It has been observed that furunculosis most often spreads among family members. Direct contact with an infected person is a major risk factor for the development of furuncles. Other independent factors include diabetes, infection with HIV, alcoholism, anemia, previous antibiotic therapy, skin diseases (especially atopic dermatitis), previous hospitalization, the multiplicity of lesions, poor personal hygiene, deficiency of mannose binding lectin and impaired function of neutrophils (El-Gilany \& Fathy, 2009; Stevens et al., 2010; Demos et al., 2012; Ibler \& Kromann, 2014). The most important risk factor of recurrent furunculosis is the exposure to the source of infection - most likely nasal carriage of $S$. aureus. Many patients after removal of furuncles have relapses of the disease (Guzik et al., 2005).

The genus Carum is an important genus of the Umbelliferae (known as Apiaceae) family (Laribi et al., 2013). Among Carum genus the most important medicinal plant is Carum carvi L. (Caraway). This crop has been cultivated for long time in different parts of the world i.e. Europe, Egypt, Australia, China and Iran (Keshavarz et al., 2013). High amount of the oil is found in the caraway seeds, which are most frequently used in the food and cosmetics industry (Darougheh et al., 2014). Caraway essential oil (CEO) extracted from caraway fruits is rich in essential oils i.e.: carvone, limonene, germacrene D and transdihydrocarvone. Also, caraway seeds contain trace amounts of other compounds including acetaldehyde, furfural, carveole, pinene, thujone, camphene and phellandrene
(Darougheh et al., 2014; Moubarz et al., 2014). Caraway is used in medicine as a remedy for indigestion, persistent ailments of the digestive system and the status of systolic. Moreover, it is used as a laxative, carminative and an appetite stimulant. CEO increases lactation in pregnant women and alleviates menstrual pain (Villarini et al., 2011; Keshavarz et al., 2013). CEO is used in phytomedicine as an antibacterial, antioxidant, antiproliferative and antitumor agent (Laribi et al., 2009b; Sadiq et al., 2010). Essential oil from C. carvi has also fungicidal, insecticidal and diuretic properties (Laribi et al., 2009a).

S. aureus is a Gram-positive, extracellular bacterium colonizing i.a. human and animal skin. In predisposing circumstances, it is responsible for the high number of skin infections, i.e. impetigo, cellulitis, folliculitis, furunculosis, subcutaneous abscesses, infected abrasions, ulcers and wounds (Krishna \& Miller, 2012) About $30 \%$ of the healthy individuals are persistent nasal $S$. aureus carriers. This bacterium permanently colonizes the anterior nares in $10-20 \%$ of the population and transiently - in 30-50\% (Ryu et al., 2014). Colonization also occurs at other body sites. Bacterium can be isolated from warm and moist skin folds (for example in the groin and under pendulous breasts) (Ibler \& Kromann, 2014). $S$ aureus nasal carriage plays an important role in chronic or recurrent furunculosis. According to Masiuk et al. (2010) patients suffering from chronic furunculosis are concomitantly the carriers of $S$. aureus localized in nose.

The aim of the study was to determine the antibacterial activity of CEO against $S$ aureus strains isolated from patients with furunculosis. Investigated strains demonstrated the presence of different virulence factors and resistance to antibiotics.

\section{MATERIAL AND METHODS}

\section{Bacterial strains}

15 S. aureus strains isolated in 2003-2008 from patients with furunculosis were analyzed in the Department of Microbiology and Diagnostic Immunology, Pomeranian Medical University in Szczecin. The material was inoculated on the following sets of solid media: Chapman agar and Columbia agar with addition of $5 \%$ sheep blood (bioMérieux. Poland). Agar plates were incubated at $35 \pm 1{ }^{\circ} \mathrm{C}$ in 
aerobic atmosphere for 24 h. S. aureus strains were identified on the basis of colonies morphology, positive catalase test, positive Staph-Kit test (bioMérieux, Poland) and positive coagulase test (Institute of Biotechnology, Sera and Vaccines, Biomed, Poland).

S. aureus ATCC 25923, S. aureus ATCC 29213 and S. aureus ATCC 43300 were used as a control strains, the property of Department of Microbiology and Diagnostic Immunology, Pomeranian Medical University in Szczecin.

\section{Detection of slime production by light microscopy}

Slime production of $S$. aureus isolates was evaluated by Congo red method with modification (crystal violet as a positive dye), according to the protocol of Korres et al. (2013). Cultures $S$. aureus were incubated in trypticase soy broth (TSB) (Difco, USA) at $35 \pm 1^{\circ} \mathrm{C}$ for $24 \mathrm{~h}$. After incubation, 2 drops of the bacteria suspension were mixed with 2 drops of crystal violet solution. Next, the mixture was smeared on a glass slide, washed with distilled water and air-dried. Slides were stained with Congo red solution $(1 \mathrm{~min})$ and air-dried. Afterwards, slides were examined with optical microscope (Olympus, Japan) and photographed. As positive result was indicated by appears a colourless halo around the bacteria cells against a pink background.

\section{DNA isolation}

Total DNA of S. aureus was isolated with a DNeasy Blood and Tissue Kit (Qiagen, Germany), according to the manufacturer's instructions. DNA was stored at $4^{\circ} \mathrm{C}$

\section{Detection of $S$. aureus virulence factors by PCR}

Set of 5 Multiplex PCR was established to detect the genes as follows: a) sea seh, sec and tst, b) see, seb, sem, sel and seo, c) sed, etd, eta and sek, d) sei, ser, seu and sep and e) sen, seg, seq and sej, as reported previously (Holtfreter et al., 2011). Single PCR was performed for the detection PVL (luk-PV), methicillinresistant $S$. aureus (MRSA) (mecA) and exfoliative toxin B (etb).

Single and Multiplex PCRs were performed with the GoTaq Flexi DNA Polymerase System (Promega, USA), as described previously (Holtfreter et al., 2011). Amplification was performed in a Thermocycler Perkin Elmer Gene Amp System 9600 (Applied Biosystems, USA). DNA was amplified with the following thermal settings: the initial denaturation $\left(2 \mathrm{~min}, 94^{\circ} \mathrm{C}\right) ; 35$ cycles of annealing at $55^{\circ} \mathrm{C}\left(94^{\circ} \mathrm{C}, 15 \mathrm{~s} ; 55^{\circ} \mathrm{C}, 20 \mathrm{~s} ; 72^{\circ} \mathrm{C}, 40 \mathrm{~s}\right)$, final extension $\left(74^{\circ} \mathrm{C}, 10\right.$ min). The amplified DNA was purified with QIAquick purification kit (Qiagen, Germany). All PCR products were resolved by electrophoresis in $1.5 \%$ agarose gels (Sigma Aldrich, Germany) in 1xTris-borate-EDTA buffer (BioRad, France) stained with ethidium bromide (Sigma Aldrich, Germany), and visualized unde UV light. 100-1500 bp DNA Ladder (Promega, USA) was used for precise sizing of PCR products. As positive controls used reference strains (Baba et al., 2002; Wu et al., 2010; Holtfreter et al., 2011).

\section{Essential oil analysis}

CEO used in this study was obtained from Vera-Nord Company, Poland (commercial producer of plant essential oils and aromatic substances). The oil exhibited a strong and characteristic odor. It was intended to the production of cosmetics and household chemistry products.

The analysis of CEO composition was performed by gas chromatography method with mass selective detector (GC-MS) using an Agilent 6890N gas chromatograph with a $5973 \mathrm{~N}$ mass selective detector. The resolution of analytes was achieved using a HP-5MSI column (5\% phenyl/95\% dimethylpolysiloxane), $30 \mathrm{~m} \times 0.25 \mathrm{~mm}$ I.D. and $0.25 \mu \mathrm{m}$ film thickness. The column temperature was programmed as follows: initial temperature $60^{\circ} \mathrm{C}$, ramp rate $8^{\circ} \mathrm{C} / \mathrm{min}$, final temperature $300^{\circ} \mathrm{C}$ (hold $5 \mathrm{~min}$ ). Helium was used as carrier gas at a flow rate of $1.2 \mathrm{~mL} / \mathrm{min}$. The injector temperature was set at $250^{\circ} \mathrm{C}$, MS quad: $150^{\circ} \mathrm{C}$; MS source: $230^{\circ} \mathrm{C}$. Mass spectra were obtained using electron impact ionization at 70 $\mathrm{eV}$ in full scan mode (mass range: $20-500 \mathrm{~m} / \mathrm{z}$ ).

Before the analysis $100 \mu \mathrm{L}$ of tested essential oil was dissolved in $1 \mathrm{~mL}$ of acetone (p.a.). The identification of the CEO components was based on the comparison of their mass spectra with the reference spectra from NIST 02 library. The relative contents of the particular compounds in essential oil were their peak area percentages in a total ion chromatogram.

\section{Screening susceptibility of bacteria to antibiotics}

The antimicrobial susceptibility of $S$. aureus isolates was performed in accordance with the European Committee on Antimicrobial Susceptibility Testing recommendations (EUCAST, 2013). Susceptibility to: ciprofloxacin CIP $\left(5 \mu \mathrm{g} \cdot \operatorname{disk}^{-1}\right)$, gentamycin - GE $\left(10 \mu \mathrm{g} \cdot \mathrm{disk}^{-1}\right)$, trimethoprim sulfamethoxazole - SXT $\left(1,25 / 23,75 \mu\right.$ g.disk $\left.{ }^{-1}\right)$, mupirocin - MUP $\left(10 \mu\right.$ g.disk $\left.{ }^{-1}\right)$ and cefoxitin - FOX (30 $\mu$ g.disk ${ }^{-1}$ ) (Becton Dickinson, USA) was evaluated with disk diffusion method performed with Mueller-Hinton agar (MHA) (bioMérieux, Poland) inoculated with a suspension $\left.\left(1.5 \times 10^{8} \mathrm{CFU}^{-1}\right)^{-1}\right)$ of the S. aureus isolates. The plates were incubated at $35 \pm 1^{\circ} \mathrm{C}$ for $18 \pm 2 \mathrm{~h}$ and inhibition zones were measured. Strains resistant to FOX were considered as MRSA.

The D-test was performed with clindamycin - CC $\left(2 \mu\right.$ g.disk $\left.{ }^{-1}\right)$ and erythromycin - E (15 $\mu$ g.disk $\left.{ }^{-1}\right)$ (Becton Dickinson, USA). These disks were placed $20 \mathrm{~mm}$ apart on the MHA plate seeded with the test strain. S. aureus strains resistant to $\mathrm{CC}$ and $\mathrm{E}$ were considered to have constitutive macrolides, lincosamides and streptogramins $\mathrm{B}$ resistance $\left(\mathrm{cMLS}_{\mathrm{B}}\right)$ phenotype. Moreover, strains with flattening of the susceptible zone of inhibition to $\mathrm{CC}$ adjacent to the $\mathrm{E}$ disk (Dshape) were considered to exhibit resistance inducible phenotype to macrolides lincosamides and streptogramins $\mathrm{B}\left(\mathrm{iMLS}_{\mathrm{B}}\right)$. Strains with circular zone around $\mathrm{CC}$ were considered to exhibit $\mathrm{MS}_{\mathrm{B}}$ phenotype (macrolides and streptogramins $\mathrm{B}$ resistance) (Saderi et al., 2011)

Broth microdilution method - determination of the minimum inhibitory concentration (MIC)

The microdilution test was conducted in 96-well plates according to Urbaniak $\boldsymbol{e t}$ al. (2014) with some modification. A dilution series of the CEO was obtained using 1\% Tween 80 (Difco, USA) solution as the solvent. The final concentrations were $100-0.5 \mu \mathrm{L} / \mathrm{mL}$. Each well received $100 \mu \mathrm{L}$ of the specific concentrations of the $\mathrm{CEO}$ and TSB with addition $10 \% \mathrm{NaCl}$ (Chempur, Poland) inoculated with $10 \mu \mathrm{L}$ bacterial suspension $\left(1.5 \times 10^{8} \mathrm{CFU} / \mathrm{mL}\right)$. The positive solvent control was completed with $100 \mu \mathrm{L}$ of $1 \%$ Tween 80 solution. The final volume in each well was $110 \mu \mathrm{L}$. The microplates were covered with parafilm and incubated for $24 \mathrm{~h}$ at $35 \pm 1{ }^{\circ} \mathrm{C}$. Inhibition of bacterial growth was confirmed by cultivation preincubated plates on Columbia agar with addition $5 \%$ sheep blood. The MIC values were defined by the lowest concentration of the CEO that inhibits the growth of the microorganism. The control wells solvent does not affect the growth of all tested bacterial strains. Each MIC test was conducted with three replicates.

\section{RESULTS AND DISCUSSION}

\section{Chemical composition of the CEO}

The results of qualitative and quantitative analysis of CEO purchased from VeraNord Company are shown in Table 1 . The main constituent of essential oil was cuminaldehyde $(46.7 \%)$ followed by $\beta$-pinene $(10.3 \%)$, durene $(9.7 \%), \gamma$ terpinene $(8.9 \%)$ and limonene $(4.7 \%)$. A total of 17 components were identified in the oil, accounting for $84.2 \%$ of the total oil (Table 1 ).

It has been proven that the main components of essential oil depends on many environmental and genetic factors and oil extraction method (Aćimović et al., 2014). A number of studies examining the essential oil content and composition of CEO have been performed. For example, research conducted by Dawidar $\boldsymbol{e t}$ al. (2010) showed that Egyptian commercial essential oil from C. carvi L. contained D-carvone $(42.61 \%)$ and D-limonene $(33.53 \%)$ as its two main components. D-carvone and limonene were also found to be the main components of the commercial CEOs provided by three independent companies (Etol, Dragoco and Pollena-Aroma) (Simic et al., 2008, Dimić et al., 2012; Gniewosz et al., 2013). Our studies demonstrated different results than these experiments in which essential oils did not contain cuminaldehyde - the main component identified in commercial CEO provided by Vera-Nord Company (Table 1). However, research conducted by Razzaghi-Abyaneh et al. (2009) showed that cuminaldehyde was present in essential oil extracted from $C$. carvi seeds. The caraway oil from Iran contained cuminaldehyde $(22.08 \%)$ and $\gamma$ terpinene $(17.86 \%)$ as its two main components, followed by $p$-cymene $(7.99 \%)$.

\section{Presence of slime}

18 S. aureus strains were examined with Congo red method. The slime production of $S$. aureus was recorded in $12(66.7 \%)$ isolates (Table 2). On the microscopic slides, a spherical, Gram-positive cocci were surrounded by a welldefined halo on a pink background (Figure 1).

Biofilm formation is important ability of bacteria and plays essential role in increased resistance to antimicrobial agents (Podbielska et al., 2010). In addition, slime interferes with phagocytosis and enhances adhesion to host tissue and inanimate objects. According to Gündoğan et al. (2006) there is lack of correlation between antibiotic resistance and slime production among $S$. aureus observed. The results showed that not all of resistance strains produced an extracellular substances. In addition, we noticed that 6 susceptible strains also produced slime (Table 2).

In our study S. aureus extracellular matrix did not affect on the MIC values. Both high and low concentration CEO did not impact on the presence of slime. It may indicate that slime did not play significant role in CEO attack on the bacteria surface. 
Table 1 Chemical composition of the commercial essential oil of C. carvi $\mathrm{L}$.

\begin{tabular}{|c|c|c|c|}
\hline Compound & CAS \# & $\begin{array}{l}\text { Retention time } \\
(\text { min) }\end{array}$ & $\begin{array}{l}\text { Relative content } \\
(\%)\end{array}$ \\
\hline$\alpha$-Thujene & $2867-05-2$ & 3.64 & 0.3 \\
\hline$\alpha$-Pinene & $80-56-8$ & 3.75 & 0.8 \\
\hline$\beta$-Pinene & $127-91-3$ & 4.39 & 10.3 \\
\hline$\beta$-Myrcene & $123-35-3$ & 4.48 & 0.3 \\
\hline$\alpha$-Phellandrene & $99-83-2$ & 4.73 & 0.4 \\
\hline Durene & $95-93-2$ & 5.09 & 9.7 \\
\hline Limonene & $138-86-3$ & 5.14 & 4.7 \\
\hline$\gamma$-Terpinene & 99-85-4 & 5.61 & 8.9 \\
\hline$p$-Cymene & 99-87-6 & 6.13 & 0.3 \\
\hline Terpinen-4-ol & $562-74-3$ & 7.61 & 0.2 \\
\hline Cuminaldehyde & $122-03-2$ & 8.92 & 46.7 \\
\hline Phellandral & $\begin{array}{c}\text { 21391-98- } \\
0\end{array}$ & 9.32 & 0.3 \\
\hline Carvacrol & $499-75-2$ & 9.85 & 0.3 \\
\hline $\begin{array}{l}\beta- \\
\text { Caryophyllene }\end{array}$ & $87-44-5$ & 11.62 & 0.2 \\
\hline$\alpha$-Bergamotene & $\begin{array}{c}\text { 17699-05- } \\
7 \\
\end{array}$ & 11.80 & 0.2 \\
\hline$\beta$-Farnesene & $\begin{array}{c}\text { 18794-84- } \\
8\end{array}$ & 12.09 & 0.3 \\
\hline$\beta$-Bisabolene & $495-61-4$ & 12.92 & 0.3 \\
\hline Total & & & 84.2 \\
\hline
\end{tabular}

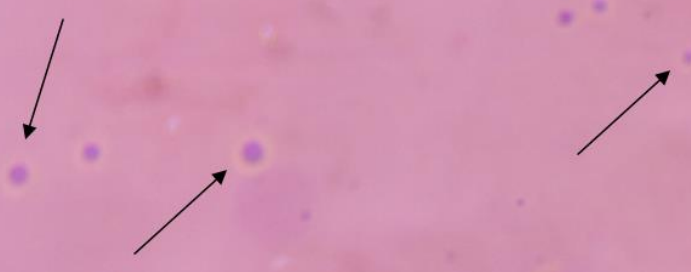

Figure 1 Microscopic views of slime formation of strain number 7 (x1,000 magnification, light microscopy) isolated from patient with furunculosis. Slimes (pointed with arrows) were visualized by double staining with crystal violet and Congo red.

\section{Distribution of genes}

In total, $80 \%(12 / 15)$ of the furunculosis strains were $l u k-P V$ positive and $13.3 \%$ (2/15) were mecA positive (Table 2). S. aureus produces variety of virulence factors, according to available data only PVL is associated with furuncles formation (Demos et al., 2012). Research performed by Masiuk et al. (2010) showed that most of methicillin-susceptible $S$. aureus (MSSA) isolates from patients with furunculosis harbored $l u k-P V$ genes. These same conclusions are reported in other reviews (Yamasaki et al., 2005; Cupane et al., 2012).

The presence of genes of exfoliative toxins eta, etb, etd and toxic shock syndrome toxin gene (tst) was not confirmed (Table 2). Exfoliative toxins A and B (ETA and ETB) are exotoxins produced by $S$. aureus, which are involved in staphylococcal scalded-skin syndrome (SSSS) and bullous impetigo (JursaKulesza et al., 2009). In our study no ETA and ETB was observed. Study conducted by Bukowski et al. (2010) shown that ETD-producing S. aureus strains are mainly isolated from furuncles or abscesses, but not from SSSS However, in our research all isolates were etd negative.

Among enterotoxins genes (SEs) (sea to seu) only seb and sel were detected. Among all tested strains, 33.3\% (5/15) were seb positive and only 1 strain $(6.7 \%)$ was sel positive (Figure 2, Table 2). These genes are located on a pathogenicity island such as SaPI3 (seb, sek, seq, or seb, sel and sek), SaPIm1/n1 (tst, sec and sel) and SAPIj50 (tst, sec and sel) (Yamamoto et al., 2013). Enterotoxin B is mainly responsible for food poisoning outbreaks and can cause toxic shock syndrome (Pinchuk et al., 2010; Karauzum et al., 2012). A recent study performed by Sina et al. (2013) showed that $S$. aureus strains isolated from skin and soft tissue infections (SSTI) such as furuncles, skin abscesses and cellulitis; and bone infections often harbored seb. Moreover, research conducted by Masiuk et al. (2010) indicated that seb was present among about 25\% strains isolated from furuncles.

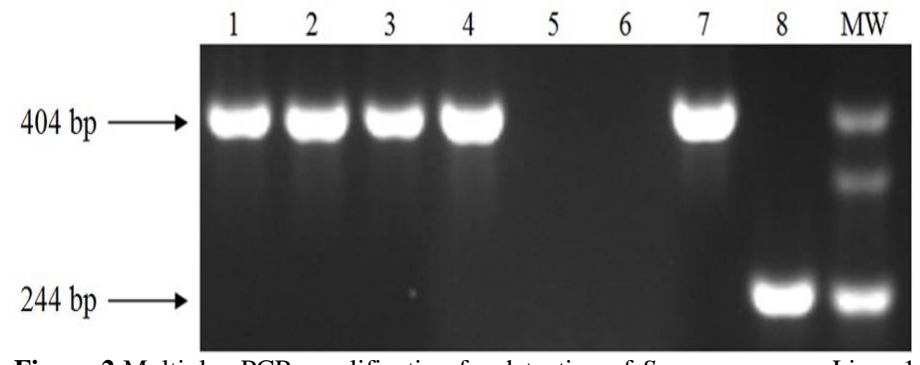

Figure 2 Multiplex PCR amplification for detection of S. aureus genes. Lines 14, 7: seb (404 bp); lines 5-6: no template DNA; line 8: sel (244 bp); MW molecular weight standard.

\section{Susceptibility testing}

2 MRSA (resistant to FOX) and 13 MSSA were isolated from furuncles. Of the all isolates, $46.7 \%(7 / 15)$ were resistant to at least one of the antibiotics tested. $46.7 \%(7 / 15)$ showed resistance to $\mathrm{CC}$ and $\mathrm{E}$ in disk diffusion testing. In D-test, $33.3 \%$ isolates exhibited $\mathrm{CMLS}_{\mathrm{B}}$ resistance and $13.3 \%$ had iMLS $\mathrm{B}_{\mathrm{B}}$ resistance phenotype. $\mathrm{MS}_{\mathrm{B}}$ resistance phenotype as not detected. Details of the prevalence of antimicrobial resistance in tested isolates are shown in Table 2.

Significant increases in prevalence of resistance to antibiotics have been observed over the past years. The misuse and overuse of antibiotics causes that antibiotics are no longer that effective in therapy. According to Lewis \& Jorgensen (2005) many community-acquired MRSA (CA-MRSA) responsible for SSTI often show $\mathrm{MLS}_{\mathrm{B}}$ mechanism. All MRSA strains tested in present study demonastrated this type of resistance mechanism. Furthermore, we have found that 33.3\% MSSA strains were resistance to $\mathrm{CC}$ and $\mathrm{E}$ (detected $\mathrm{CMLS}_{\mathrm{B}}$ and $\mathrm{iMLS}_{\mathrm{B}}$ resistance phenotypes). Study performed by Patel $\boldsymbol{e t}$ al. (2006) indicated that $\mathrm{iMLS}_{\mathrm{B}}$ was detected in 33\% CA-MRSA and 56\% hospital-acquired MRSA isolates. Research conducted by Saderi et al. (2011) showed similar results. In this experiment $S$. aureus strain was isolated from the purulent lesions of the skin. Prevalence of $\mathrm{cMLS}_{\mathrm{B}}$ and $\mathrm{iMLS}_{\mathrm{B}}$ resistance phenotypes were $92.8 \%$ and $6.4 \%$, respectively. This indicates that $S$. aureus strains with $\mathrm{cMLS}_{\mathrm{B}}$ phenotype were much more frequent than with $\mathrm{iMLS}_{\mathrm{B}}$ phenotype, which is similar to our results.

\section{The activity of CEO against tested bacterial strains}

Both control and all clinical strains derived from patients with furunculosis were sensitive to CEO (Table 2). The inhibition of growth for all analyzed strains $S$. aureus after applying of CEO was observed. In the case of MSSA strains, the MIC values of essential oil were $26.7 \pm 5.8-66.7 \pm 11.5 \mu \mathrm{L} / \mathrm{mL}$, which was larger than that produced by the MIC values of control strains number 1 and 2 (both $10 \pm 8.7 \mu \mathrm{L} / \mathrm{mL}$ ). In the case of MRSA strains, the MIC values of CEO were $6.67 \pm 2.9-30 \pm 10 \mu \mathrm{L} / \mathrm{mL}$, which was also larger than that produced by the MIC values of control strain number $16(11.7 \pm 7.6 \mu \mathrm{L} / \mathrm{mL})$. The largest number of isolates was inhibited by concentrations of $46.7 \pm 5.8 \mu \mathrm{L} / \mathrm{mL}$ (4 antibiotic-susceptible strains and $1 \mathrm{cMLS}_{\mathrm{B}}$ strain).

In recent years, interest in essential oils is significantly observed. Essential oils are used in natural medicine to treat a wide range of infections caused by bacteria. Commercial essential oil was tested against $S$. aureus and demonstrated antibacterial activity against these strains (Gniewosz et al., 2013; Alboofetileh $\boldsymbol{e t}$ al., 2014). Seidler-Łożykowska et al. (2013) have studied the activity of CEO obtained from fruit originated from different genotypes against $S$. aureus. The authors demonstrated that MIC analyzed essential oil ranged from $0.2-1.6$ $\mathrm{mg} / \mathrm{mL}$. Moreover, in this study the authors have proved that carvone can be recognized as a one of the active component. Others have reported MIC of CEO against $S$. aureus varied from 0.1 to $3 \mu \mathrm{L} / \mathrm{mL}$ (Di Pasqua et al., 2005; Mohamed et al., 2013; Simic et al., 2008; Tarek et al., 2014). In these studies, GC-MS analysis of essential oil shown that the main components were carvone and limonene in contrast to our study. Moreover, tested by us CEO demonstrated higher MIC against $S$. aureus strains responsible for furunculosis than abovementioned results. 
Table 2 Characteristic of S. aureus strains

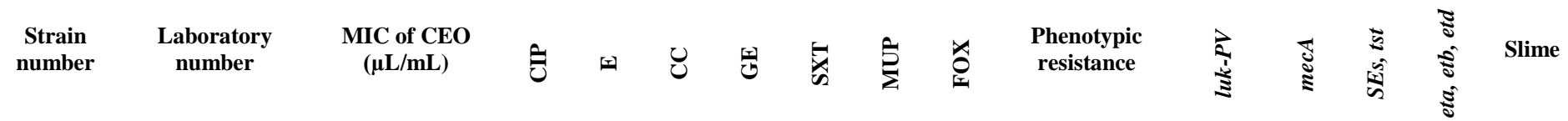

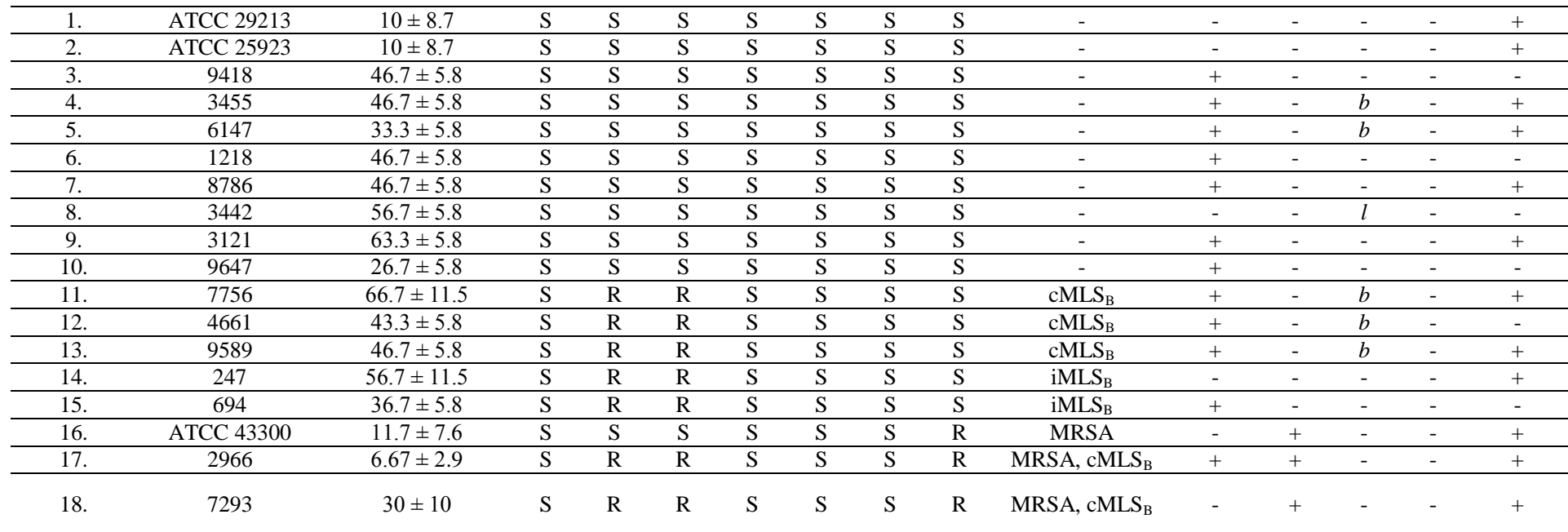

Legend: MIC - minimal inhibitory concentration, CEO - caraway essential oil, R - resistant, S - susceptible, CIP - ciprofloxacin, E - erythromycin, CC - clindamycin, GE - gentamycin, SXT -

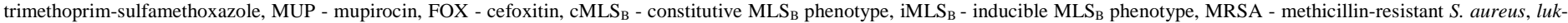
$P V$ - Panton-Valentine leukocidin gene, mecA - methicillin resistance gene, SEs - enterotoxins genes, tst - toxic shock syndrome toxin gene, eta, etb, etd - exfoliative toxin A, B, D genes. MIC values are expressed as means \pm standard deviation.

According to Peter (2012) CEO extracted from C. carvi L. is generally safe for internal and has no toxic effect. Although it may cause skin irritation if used in high concentration. Moreover, CEO can irritate the eyes. Therefore, CEO should not be used directly on the skin. In addition, study performed by Morshedi $\boldsymbol{e t}$ al. (2015) showed that cuminaldehyde (the main component identified in commercial CEO provided by Vera-Nord Company) is a nontoxic compound. These authors demonstrated no toxic effect on the cells.

\section{CONCLUSION}

There were no significant differences in MIC values depending on the susceptible/resistance to antibiotics, virulence genes and presence of slime. Commercial CEO has inhibitory effects on growth of $S$. aureus strains isolated from patients with furunculosis, regardless of the degree of resistance to antibiotics and virulence of the strain. CEO can be used as an alternative antibacterial agent in the treatment of furunculosis (especially in persons suffer from recurrent episodes).

Acknowledgments: All the authors acknowledge Department of Microbiology and Diagnostic Immunology, Pomeranian Medical University in Szczecin for the financial support in carrying out this work. We are extremely grateful to many colleagues and all the individuals who were provided us with reagents.

\section{REFERENCES}

Aćimović, M. G., Oljača, S. I., Tešević, V. V., Todosijević M. M. \& Djisalov, J. N. (2014). Evaluation of caraway essential oil from different production areas of Serbia. HortScience, 41, 122-30.

Alboofetileh, M., Rezaei, M., Hosseini H. \& Abdollahi, M. (2014). Antimicrobia activity of alginate/claynanocomposite films enriched with essential oils against three common foodborne pathogens. Food Control, 36(1), 1-7. http://dx.doi.org/10.1016/j.foodcont.2013.07.037

Baba, T., Takeuchi, F., Kuroda, M., Yuzawa, H., Aoki, K., Oguchi, A., Nagai, Y., Iwama, N., Asano, K., Naimi T., Kuroda, H., Cui, L., Yamamoto, K. \& Hiramatsu, K. (2002). Genome and virulence determinants of high virulence communityacquired MRSA. Lancet, 359(9320), 1819-1827. http://dx.doi.org/10.1016/s0140$\underline{6736(02) 08713-5}$

Bukowski, M., Wladyka B. \& Dubin, G. (2010). Exfoliative toxins of $\begin{array}{llll}\text { Staphylococcus } \quad \text { aureus. } & \text { Toxins, } & \text { 2, }\end{array}$ http://dx.doi.org/10.3390/toxins2051148

Cupane, L., Pugacova, N., Berzina, D., Cauce, V., Gardovskaand D. \& Miklaševics, E. (2012). Patients with Panton-Valentine leukocidin positvie Staphylococcus aureus infections run an increased risk of longer hospitalisation. International Journal of Molecular Epidemiology and Genetics, 3(1), 48-55.

Darougheh, F., Barzegar M. \& Sahari, M. A. (2014). Antioxidant and anti-fungal effect of caraway (Carum carvi L.) essential oil in real food system. Current
Nutrition \& Food

Science,

$10(1)$

$70-76$

http://dx.doi.org/10.2174/1573401310666140306004839

Dawidar, A. M., Abdel-Mogib, M., Abou-Elzahab, M. M., Berghot, M. A., Mahfouz, M. \& El-Ghorab, A. H. (2010). Effect of photo-oxygenation on biological activities of some commercial Egyptian essential oils. Revista Latinoamericana de Química, 38(3), 168-179.

Demos, M., McLeod, M. P. \& Nouri, K. (2012). Recurrent furunculosis: a review of the literature. British Journal of Dermatology, 167(4), 725-732. http://dx.doi.org/10.1111/j.1365-2133.2012.11151.x

Dimić, G. R., Kocić-Tanackov, S. D., Jovanov, O. O., Cvetković, D. D., Markov, S. L. \& Velićanski, A.S. (2012). Antibacterial activity of lemon, caraway and basil extracts on Listeria spp. Acta Periodica Technologica, 43, 239-246. http://dx.doi.org/10.2298/apt1243239d

Di Pasqua, R., De Feo, V., Villani, F., \& Mauriello, G. (2005). In vitro antimicrobial activity of essential oils from Mediterranean Apiaceae Verbenaceae and Lamiaceae against foodborne pathogens and spoilage bacteria. Annals of Microbiology, 55(2), 139-143.

El-Gilany, A. H. \& Fathy, H. (2009). Risk factors of recurrent furunculosis Dermatology Online Journal, 15(1), 16.

European Committee on Antimicrobial Susceptibility Testing (2013). EUCAST guidelines for detection of resistance mechanisms and specific resistances of clinical and/or epidemiological importance. EUCAST, Warsaw, Poland: http://www.korld.edu.pl/pdf/eucast/EUCAST_breakpoints_tlumaczenie_versja\%2 05_2015-strona.pdf

Gniewosz, M., Kraśniewska, K., Woreta, M. \& Kosakowska, O. (2013) Antimicrobial activity of a pullulan-caraway essential oil coating on reduction of food microorganisms and quality in fresh baby carrot. Journal of Food Science, 78(8), 1242-1248. http://dx.doi.org/10.1111/1750-3841.12217

Guzik, T. J., Bzowska, M., Kasprowicz, A., Czerniawska-Mysik, G., Wójcik, K., Szmyd, D., Adamek-Guzik, T., \& Pryjma, J. (2005). Persistent skin colonization with Staphylococcus aureus in atopic dermatitis: relationship to clinical and immunological parameters. Clinical \& Experimental Allergy, 35(4), 448-455. http://dx.doi.org/10.1111/j.1365-2222.2005.02210.x

Gündoğan, N., Citak, S. \& Turan, E. (2006). Slime production, DNase activity and antibiotic resistance of Staphylococcus aureus isolated from raw milk, pasteurised milk and ice cream samples. Food Control, 17(5), 389-392. http://dx.doi.org/10.1016/j.foodcont.2005.01.006

Holtfreter, S., Jursa-Kulesza, J., Masiuk, H., Verkaik, N. J., de Vogel, C., Kolata J., Nowosiad, M., Steil, L., van Wamel, W., van Belkum A., Völker, U., GiedrysKalemba, S. \& Bröker, B. M. (2011). Antibody responses in furunculosis patients vaccinated with autologous formalin-killed Staphylococcus aureus. European

Journal of Clinical Microbiology \& Infectious Diseases, 30(6), 707-717. http://dx.doi.org/10.1007/s10096-010-1136-3 
Ibler, K. S. \& Kromann, C. B. (2014). Recurrent furunculosis - challenges and management: a review. Journal of Clinical, Cosmetic and Investigational Dermatology, 7, 59-64. http://dx.doi.org/10.2147/ccid.s35302

Jursa-Kulesza, J., Kordek, A., Kopron, K., Wojciuk, B. \& Giedrys-Kalemba, S. (2009). Molecular studies of an impetigo bullosa epidemic in full-term infants Neonatology, 96(1), 61-68. http://dx.doi.org/10.1159/000204961

Karauzum, H., Chen, G., Abaandou, L., Mahmoudieh, M., Boroun, A. R., Shulenin, S., Devi, V. S., Stavale, E., Warfield, K. L., Zeitlin, L., Roy, C. J., Sidhu, S. S. \& Aman, M. J. (2012). Synthetic human monoclonal antibodies toward staphylococcal enterotoxin B (SEB) protective against toxic shock syndrome. Journal of Biological Chemistry, 287(30), 25203-25015. http://dx.doi.org/10.1074/jbc.m112.364075

Keshavarz, A., Minaiyan, M., Ghannadi, A. \& Mahzouni, P. (2013). Effects of Carum carvi L. (Caraway) extract and essential oil on TNBS-induced colitis in rats. Research in Pharmaceutical Science, 8(1), 1-8.

Korres, A. M. N., Aquije, G. M., Buss, D. S., Ventura, J. A., Fernandes, P. M. B \& Fernandes, A. A. R. (2013). Comparision of biofilm and attachment mechanisms of a phytopathological and clinical isolate of Klebsiella pneumoniae subsp. pneumoniae. The Scientific World Journal, 6 http://dx.doi.org/10.1155/2013/925375

Krishna, S. \& Miller, L. S. (2012). Host-pathogen interactions between the skin and Staphylococcus aureus. Current Opinion in Microbiology, 15(1), 28-35 http://dx.doi.org/10.1016/j.mib.2011.11.003

Laribi, B., Bettaieb, I., Kouki, K., Sahli, A., Mougou, A. \& Marzouk, B. (2009a) Water deficit effects on caraway (Carum carvi L.) growth, essential oil and fatty acid composition. Industrial Crops and Products, 30(3), 372-379. http://dx.doi.org/10.1016/j.indcrop.2009.07.005

Laribi, B., Kouki, K., Mougoua, A. \& Marzouk, B. (2009b). Fatty acid and essential oil composition of three Tunisian caraway (Carum carvi L.) seed ecotypes. Journal of the Science of Food Agriculture, 90, 391-396. http://dx.doi.org/10.1002/jsfa.3827

Laribi, B., Kouki, K., Bettaieb, T., Mougou, A. \& Marzouk, B. (2013). Essential oils and fatty acids composition of Tunisian, German and Egyptian caraway (Carum carvi L.) seed ecotypes: A comparative study. Industrial Crops and Products, 41, 312- 318. http://dx.doi.org/10.1016/j.indcrop.2012.04.060

Lewis, J. S. \& Jorgensen, J. H. (2005). Inducible clindamycin resistance in Staphylococci: should clinicians and microbiologists be concerned? Clinical Infectious Diseases, 40(2), 280-285. http://dx.doi.org/10.1086/426894

Masiuk, H., Kopron, K., Grumann, D., Goerke, C., Kolata, J., Jursa-Kulesza, J., Giedrys-Kalemba, S., Bröker, B. M. \& Holtfreter, S. (2010). Association of recurrent furunculosis with Panton-Valentine leukocidin and the genetic background of Staphylococcus aureus. Journal of Clinical Microbiology, 48(5), 1527-1535. http://dx.doi.org/10.1128/jcm.02094-09

Mohamed, S. H. S., Zaky, W. M., Kassem, J. M., Abbas, H. M., Salem, M. M. E. \& Said-Al Ahl, H. A. H. (2013). Impact of antimicrobial properties of some essential oils on cheese yoghurt quality. World Applied Sciences Journal, 27(4), 497-507.

Morshedi, D., Aliakbari, F., Tayaranian-Marvian, A., Fassihi, A., Pan-Montojo, F. \& Pérez-Sánchez, H. (2015). Cuminaldehyde as the major component of Cuminum cyminum, a natural aldehyde with inhibitory effect on alpha-synuclein fibrillation and cytotoxicity. Journal of Food Science, 80(10), H2336-H2345. http://dx.doi.org/10.1111/1750-3841.13016

Moubarz, G., Taha, M. M. \& Mahdy-Abdallah, H. (2014). Antioxidant effect of Carum carvi on the immune status of streptozotocin - induced diabetic rats infected with Staphylococcus aureus. World Applied Sciences Journal, 30(1), 63 69

Patel, M., Waites, K. B., Moser, S. A., Cloud, G. A. \& Hoesley, C. J. (2006) Prevalence of inducible clindamycin resistance among community- and hospitalassociated Staphylococcus aureus isolates. Journal of Clinical Microbiology, 44(7), 2481-2484. http://dx.doi.org/10.1128/jcm.02582-05

Peter, K.V. (2012). Handbook of herbs and spices (second edition) (Vol. 2) Philadelphia: Woodhead Publishing Limited

Pinchuk, I. V., Beswick, E. J. \& Reyes, V. E. (2010). Staphylococcal enterotoxins, Toxins 2(8), 2177-2197. http://dx.doi.org/10.3390/toxins2082177

Podbielska, A., Galkowska, H., Stelmach, E., Mlynarczyk, G. \& Olszewski, W L. (2010). Slime production by Staphylococcus aureus and Staphylococcus epidermidis strains isolated from patients with diabetic foot ulcers. Archivum Immunologiae et Therapia Experimentalis, 58(4), 321-324. http://dx.doi.org/10.1007/s00005-010-0079-9

Razzaghi-Abyaneh, M., Shams-Ghahfarokhi, M., Rezaee, M. B., Jaimand, K., Alinezhad, S., Saberi, R. \& Yoshinari, T. (2009). Chemical composition and antiaflatoxigenic activity of Carum carvi L., Thymus vulgaris and Citrus aurantifolia essential oils. Food Control, 20(11), 1018-1024 http://dx.doi.org/10.1016/j.foodcont.2008.12.007

Ryu, S., Song, P. I., Seo, C. H., Cheong, H. \& Park, Y. (2014). Colonization and infection of the skin by $S$. aureus: immune system evasion and the response to cationic antimicrobial peptides. International Journal of Molecular Sciences, 15(5), 8753-8772. http://dx.doi.org/10.3390/ijms15058753

Saderi, H., Emadi, B. \& Owlia, P. (2011). Phenotypic and genotypic study of macrolide, lincosamide and streptogramin B (MLSB) resistance in clinical isolates of Staphylococcus aureus in Tehran, Iran. Medical Sciences Monitor, 17(2), 48-53. http://dx.doi.org/10.12659/msm.881386

Sadiq, S., Nagi, A. H., Shahzad, M. \& Zia, A. (2010). The Reno-protective effect of aqueous extract of Carum carvi (Black zeera) seeds in streptozotocin induced diabetic nephropathy in rodents. Saudi Journal of Kidney Diseases and Transplantation, 21(6), 1058-1065.

Seidler-Łożykowska, K., Kędzia, B., Karpińska, E. \& Bocianowski, J. (2013) Microbiological activity of caraway (Carum carvi L.) essential oil obtained from different origin. Acta Scientiarum Agronomy, 35(4), 495-500. http://dx.doi.org/10.4025/actasciagron.v35i4.16900

Simic, A., Rančic, A., Sokovic, M. D., Ristic, M., Grujic-Jovanowic, S. Vukojevic, J. \& Marin, P. D. (2008). Essential oil composition of Cymbopogon winterianus and Carum carvi and their antimicrobial activities. Pharmaceutical Biology, 46(6), 437-441. http://dx.doi.org/10.1080/13880200802055917

Sina, H., Ahoyo, T. A., Moussaoui, W., Keller, D., Bankolé, H. S., Barogui, Y., Stienstra, Y., Kotchoni, S. O., Prévost, G. \& Baba-Mouss, L. (2013). Variability of antibiotic susceptibility and toxin production of Staphylococcus aureus strains isolated from skin, soft tissue, and bone related infections. BMC Microbiology, 13(1), 1-9. http://dx.doi.org/10.1186/1471-2180-13-188

Stevens, A. M., Hennessy, T., Baggett, H. C., Bruden, D., Parks, D. \& Klejka, J. (2010). Methicillin-resistant Staphylococcus aureus carriage and risk factors for skin infections, Southwestern Alaska, USA. Emerging Infectious Diseases, 16(5), 797-803. http://dx.doi.org/10.3201/eid1605.091851 